\title{
Family support, discrimination, and quality of life among ART-treated HIV-infected patients: a two-year study in China
}

\author{
Jun-Fang Xu' ${ }^{1}$, Zhong-Qiang Ming ${ }^{2}$, Yu-Qian Zhang ${ }^{3}$, Pei-Cheng Wang ${ }^{1}$, Jun Jing ${ }^{1,4}$ and Feng Cheng ${ }^{1,5^{*}}$
}

\begin{abstract}
Background: By September 2016, approximately 653,865 people in China were living with HIV/AIDS (PLWHA) and 492,725 people were receiving antiretroviral therapy (ART). PLWHA frequently experience discrimination in all domains of their personal and social lives. The World Health Organization includes discrimination in its list of social determinants of health factors that have been linked to poor physical and psychological health. This paper identifies the family support enjoyed and discrimination faced by people infected with HIV and examines the effect they have on patients' quality of life (QOL) as they undergo ART in China.
\end{abstract}

Methods: We conducted this observational cohort study of ART-treated patients with HIV in Guangxi Province using a questionnaire survey at baseline, 6, 12, and 24 months, starting in 2010. Descriptive analysis was used to describe the demographic characteristics (e.g., age, sex, educational level, marital status, and employment status) of participants. Generalized estimating equations (GEE) were employed to examine the relationships between family support, discrimination, and QOL.

Results: In the study, $90.4 \%(n=281)$ of patients received family support at baseline, here defined as the initiation of ART, $91.8 \%(n=244)$ received family support 6 months into ART, 95.5\% $(n=220)$ at 12 months, and $94.3 \%(n=230)$ at 24 months. The proportion of patients who did not feel discriminated against by their families was $87.2 \%(n=274)$ at baseline, 90.4\% $(n=229) 6$ months into ART, 90.0\% $(n=210)$ at 12 months, and 94.5\% $(n=219)$ at 24 months. Patients' overall QOL scores were positively associated with having received family support ( $O R=2.74, P=0.040,95 \% \mathrm{Cl}: 1.68-4.47)$ , not feeling discriminated against by their families $(O R=1.3, P=0.041,95 \% C l: 1.07-1.59)$ or discrimination from patients themselves, including never experiencing fear of abandonment by family $(O R=2.05, P=0.025,95 \% \mathrm{Cl}: 1.49-2.82)$.

Conclusions: Family support along with no or minimal discrimination was found to contribute to QOL among people infected with HIV. Their overall QOL tended to improve significantly as ART continued. This suggests that strategies meant to improve and strengthen family support, care for PLWHA, and promote HIV screening among high-risk populations should be explored by both policy makers and researchers.

Keywords: Quality of life, Family support, Discrimination, People infected with HIV, China

\footnotetext{
* Correspondence: fcheng@mail.tsinghua.edu.cn

${ }^{1}$ Research Center for Public Health, School of Medicine, Tsinghua University,

Beijing, China

${ }^{5}$ Center for Global Health and Infectious Diseases of Tsinghua University,

Beijing, China

Full list of author information is available at the end of the article
} 


\section{Multilingual abstracts}

Please see Additional file 1 for translations of the abstract into the five official working languages of the United Nations.

\section{Background}

The Chinese Center for Disease Control and Prevention estimated that the prevalence of HIV remained greater than $0.4 \%$. As of September 2016, approximately 653,865 people in China were living with HIV/AIDS (PLWHA) and 492,725 patients were receiving antiretroviral therapy (ART) $[1,2]$. About $15 \%$ of all PLWHA are young people aged 15 to 24, among whom the incidence of HIV increased from $6.9 \%$ in 2006 to $23 \%$ in 2012 (www.ncstdc.org). The average annual growth in the rate of 15 to 24 year old students infected with HIV reached $35 \%$ in 2015 , and $65 \%$ of these students infected with HIV were 18-22 years old and studying at universities. This may be because young students' minds are open but they lack sexual knowledge and have limited capacity for self-examination and self-awareness [1]. The infection rate in China's south-western provinces and autonomous region, Yunnan, Guangxi, and Sichuan, is especially high. These three provinces are home to $12.9 \%$ of China's total population, but they account for $45 \%$ of all PLWHA in the entire country [3]. Guangxi Zhuang Autonomous Region sees more than 5000 new cases of HIV every year, with an incidence of $0.1 \%$ [3]. In 2003, a new administration led by President $\mathrm{Hu}$ Jintao, Premier Wen Jiabao, and Vice Premier and Health Minister Wu Yi substantially accelerated the commitment to and implementation of evidence-based HIV policies. Under this administration, a number of initiatives were introduced, including the "Four Free and One Care" policy in December 2003, which provides free antiretroviral drugs to AIDS patients who live in rural areas and those without insurance who live in urban areas, free voluntary counselling and testing, free drugs to HIV-infected pregnant women to prevent mother-to-child transmission, HIV testing of new-born babies, free schooling for AIDS orphans, and care and economic assistance to the households of people living with HIV/AIDS. It has expanded to more than 120 sites nationwide with the aim of controlling the spread of AIDS. Special funds have been earmarked for funding highly active ART for HIV patients. In China, sexual transmission (i.e., homosexual transmission and heterosexual transmission) and the sharing needles for illegal drug use are the main causes of infection [3].

Ever since the human immunodeficiency virus (HIV) was first identified, indicators of quality of life (QOL) of the individuals carrying it and the mortality rates of AIDS patients have undergone substantial changes. The advent of combined antiretroviral therapy has contributed significantly to those changes [4-6], and highly active ART allows PLWHA to live longer. However, the diagnosis of HIV infection and subsequent antiretroviral treatment often cause both physical and emotional suffering, which diminish the patient's QOL [7-9]. Moreover, multiple sources of stress, such as the disease itself, financial burdens, stigma, discrimination and pressure from worrying about family reactions and needs, have negative effects on the QOL of PLWHA. Preventive behaviours such as condom use, HIV test-seeking behaviour, and care-seeking behaviour upon diagnosis can also be affected by the patient's negative feelings [10-12].

Clinical and empirical findings suggest that family can be a significant source of stress for PLWHA, second only to that of the disease itself $[13,14]$. However, strong support and little stress from family may increase the QOL of PLWHA. They can also inform the design of family-cantered HIV-related interventions by increasing the participation rate and level of adherence to antiretroviral treatment and by reducing the rate of loss to follow-up rate [15]. A growing number of studies have shown that, programs for PLWHA need to engage the patients' families in order to be successful $[16,17]$. Support from family and partners can also improve adherence to therapy, which is the first important factor to be addressed in the planning of HAART services [18]. Furthermore, among HIV-infected adults whose relationships between social support and psychological adjustment were examined, greater support, including financial and spiritual support, was found to reduce psychological distress, such as symptoms of depression $[19,20]$.

The disclosure of serostatus by PLWHA to their partners, family, and friends is an important means of reducing the incidence of HIV infection and improving HIV treatment and care [21-23]. Over the past 15 years, notification of partners' HIV status has been a major public health strategy in HIV prevention in China [24]. However, disclosing HIV serostatus to partners, family, and friends is still a difficult decision for many HIV-infected people in the context of high level of stigma and discrimination associated with HIV status and the risk of rejection, abandonment, violence, abuse, loss of custody of children, loss of property, and ostracism, all of which are common for PLWHA, especially women [25]. Chinese society is family-oriented, which means many individual experiences become, or are inseparable from, family matters. In this way, the whole family is often stigmatized if any one member is publicly known to be HIV positive. Others may believe that the entire family engages in unhealthy or unwholesome behaviour. More often, the family is blamed for permitting the risky behaviours that led to HIV infection. Many studies have reported similar findings regarding the impact of HIV on whole families [26-28]. The lack of necessary HIV-related knowledge and skills in communicating about sensitive topics (e.g., 
sexual behaviours and HIV transmission) can be also a barrier to planning an appropriate and smooth disclosure [29].

After testing positive, PLWHA will often experience HIV-related stigma and discrimination from healthy family members because it is understood that risky behaviours (such as drug use and commercial sex) lead to disease and because they resent the patient for the damage done to the reputation of the entire family. However, family support is one of the most important factors affecting how patients adapt to illness [30]. The presence of support may improve psychological and emotional well-being and reduce stress [31]. Yet few studies have explored the effect of family support and discrimination on PLWHA's QOL in China. This study analyses family support for and discrimination against people infected with HIV undergoing ART at four different points in time and examines the relationship between the QOL, family support, and discrimination.

\section{Methods}

\section{Setting and study design}

An observational cohort study of patients initiating ART was conducted in five hospitals and clinics located in Guangxi Zhuang Autonomous Region in 2010, which treat $11.3 \%$ of PLWHA in China: Pingxiang People's Hospital ART Clinic, Guangxi CDC ART Clinic in Nanning City, the 4th Nanning Hospital ART Clinic, Guigang City People's Hospital ART Department, and Guilin 3rd People's Hospital. Since Guangxi began ART in 2004, good progress has been made. We selected five health facilities based on the following criteria: (1) Whether they provide ART services as stipulated in China's National ART Guidelines; (2) whether the patients there are willing to participate in the study and adhere to its protocol; (3) whether there had been an adequate number of outpatients, here an average number of ten or more over the previous three months.

Male and female people infected with HIV aged 18 years or older who had initiated ART from the one of the five clinics mentioned above were eligible to participate in the study. People infected with HIV were invited to participate and provided an informed consent form to complete if they agreed to participate in the study. Specific criteria for participation in the cohort study were as follows: (1) They had to meet ART admission criteria as stipulated in national ART guidelines; (2) HIV-positive status and undergoing ART for the first time during the recruitment period; (3) willingness to participate and provide a signed informed consent form; (4) sufficient physical capacity to complete questionnaire surveys, as assessed by the physicians in the hospitals or clinics. China's national ART admission criteria included the following: (1) Confirmed HIV positive status; (2) meeting the medical criteria for admission (clinical and laboratory); (3) sufficient preparation for treatment (including clinical, adherence, education, and family and peer support).

All new patients who began ART were screened during normal work hours to determine if they met the inclusion criteria and, if eligible, were invited to participate in the study. Patients who expressed an interest in participating in the study to their attending physician were referred to an interviewer, who read them the standard informed consent in the ART clinic. Patients were asked to sign the consent form if they agreed to participate. After completing the informed consent procedure, the participant was then given the detailed baseline and follow-up questionnaires in a face-to-face interview in a private setting. A total of 332 subjects were recruited for the study. To protect the patients' privacy, all interviews were conducted in a small room in the hospital or clinic. Patients underwent regular follow-up and appointments were made with them to complete the 6-month, 12month, and 24-month surveys. The interviewer then checked the hard copies of the questionnaires for accuracy and completeness within 1-2 days. Whenever possible, any errors in questionnaire administration were addressed by discussion with the participants by telephone. The interviewer would contact the study participant and confirm schedules for both the initial and follow-up visits on an ongoing basis and develop a spreadsheet to keep track of those appointments. Figure 1 shows the detailed procedures through which participants were recruited.

\section{Data collection}

Structured questionnaires were developed specifically for this study. They included the following key components: demographics and socioeconomics, health-related quality of life (HR-QOL), and family support and discrimination, which included whether the participant told his or her the family he or she was positive for HIV, what support does the family provided, whether the participant felt that his or her family had discriminated against him or her, and similar questions. Quality of life data were obtained using the Chinese version of the WHOQOLHIV BREF instrument. The WHOQOL-HIV-Brief (Chinese version) is a cross-cultural instrument that contains 31 items developed from the original 100-term questionnaire. It contains six domains, physicality, psychology, independence, social relationships, environment, and spirituality. Each item has a five-point ordinal response scale scoring from 1 to 5 . Higher scores indicate better quality of life [103]. Reliability and validity of the structured questionnaires were examined using Cronbach's $\alpha$ coefficient and the results $(\alpha=0.946)$ demonstrated that the questionnaire exhibited high reliability and validity. The quantitative 


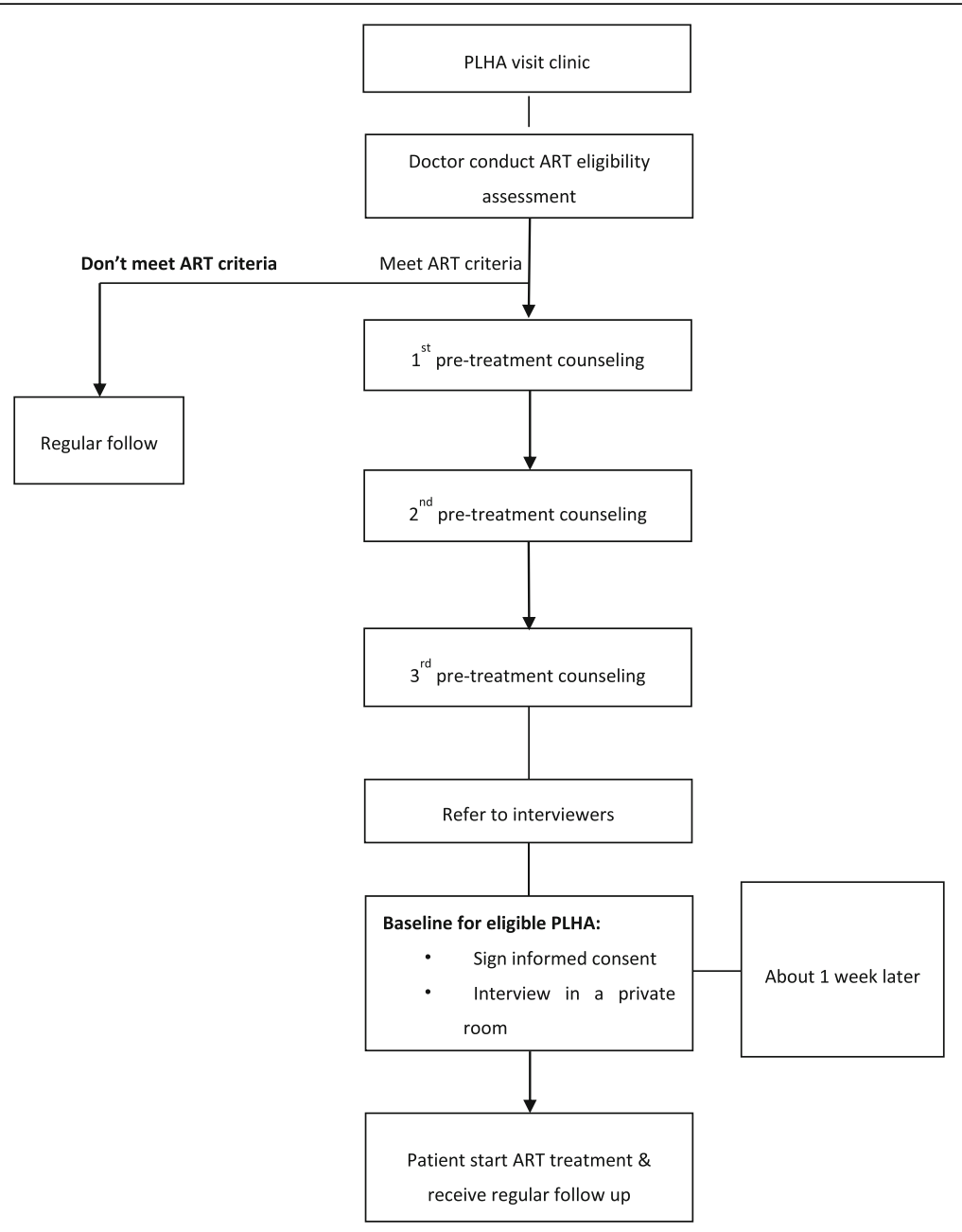

Fig. 1 Detailed procedures by which participants were recruited

questionnaire surveys were conducted at four points in time including baseline of initial ART, and after 6, 12, and 24 months of ART.

\section{Statistical analysis}

Before data analysis, different surveys and variables were checked for logic using SAS, covering ranges, consistency, logical relationships, and other factors. Whenever such checks revealed errors, original hard copy questionnaires and medical records were revisited for final confirmation and correction. Some participants gave answers of "I don't know" or made no response at all. These were treated as "no". All data from different sites were merged into a unified dataset based on the variables in the questionnaire using SAS 9.1.

Sample size calculations were based on the following assumptions: Significance (alpha) was set to 5\%; power (beta) to $90 \%$; desired changes in QOL over time to 0.8 for all QOL domains; $20 \%$ was allowed for loss to follow up. Given these considerations and calculations, it was determined that a sample size of approximately 300 people infected with HIV was adequate. About $40 \%$ of the cohort participants were from Guangxi CDC ART clinic in Nanning City, 30\% from the 4th Nanning Hospital ART Clinic, 20\% from Pingxiang People's Hospital ART Clinic, and about 10\% from Guigang City People's Hospital and Guilin 3rd People's Hospital.

Descriptive analysis was used to describe the demographic characteristics (e.g., age, sex, educational level, marital status, occupation, living status, and monthly household income) of participants. Generalized estimating equations (GEE) with standardized counselling sessions were used to analyse the effect of family support and discrimination on patients' overall quality of life.

\section{Results}

A total of 332 subjects were recruited for the study. 267 (80.4\%), 260 (78.3\%), and $246(74.0 \%)$ continued to 
participate at the 6-month, 12-month, and 24-month periods, respectively (Table 1 ). Continued participation represented acceptable retention rates. Attrition was attributed to an inability to conduct follow-up, death, and transfer from the study facilities. Of the baseline participants, 226 (68.1\%) were male and 106 (31.9\%) were female. The average age was 39.6 years (range 20.2-76.5); 42.2 (a range of 19.9-79.5) for men and 38.3 (range 22.274.1) for women. Here, 110 participants had a primary school education or less, accounting for $33.2 \%$ of the cohort, 150 participants (45.3\%) had a secondary school education, and $71(21.5 \%)$ had a high school education or above; 218 (65.7\%) were married or cohabitating, and 114 (34.3\%) were unmarried and not cohabitating. The majority of participants $(62.0 \%)$ were farmers or unemployed and 125 (38.0\%) were employed. $43(14.8 \%)$ participants currently lived alone. A majority (59.4\%) of the patients' average monthly household incomes were below 1000 RMB (1000 RMB = 144.7 US\$). There were no significant changes in the study participants' demographics over time (Table 2).

\section{Quality of life of ART patients at baseline upon initiation of ART and after 6, 12, and 24 months of ART}

At the baseline assessment, average scores on QOL were approximately at middle level: Overall perception of QOL from patients themselves 11.3, overall perception of health from patients themselves 10.3, physical health 12.5 , psychological health 11.3 , level of independence 11.6, social relationships 11.4, environment 11.4, spirituality 12.0, overall QOL score 11.5 .

At the 6-month survey, QOL scores were as follows: overall perception of quality of life 12.6 , overall perception of health 12.9, physical health 14.4, psychological health 13.1, level of independence 13.6, social relationships 12.0 , environment 12.4, spirituality 13.1 , overall QOL score 13.0. All of these average scores were significantly higher after 6 months of ART.

The 12-month survey yielded the following participant perception of QOL: overall perception on QOL 12.6, overall perception on health 13.0, physical health 14.2, psychological health 12.8 , level of independence 13.7 , social relationships 11.6, environment 12.0, spirituality 12.9, overall QOL score 12.8 .
At the 24-month survey, QOL scores were as follows: overall perception on quality of life 13.4, overall perception on health 13.7, physical health 14.8 , psychological health 13.6, level of independence 13.8, social relationships 11.8 , environment 12.2 , spirituality 13.8 , and overall QOL score 13.4.

Some scores, including physical, psychological, social relationship, environment, spiritually, and overall QOL scores were lower at 12 months than at 6 months, although they had increased again by the 24-month survey. All scores were significantly higher at the 24-month follow-up assessment than that at 12 -month assessment (Fig. 2).

\section{Family support and discrimination}

Most of the patients (81.3\%) disclosed their HIV positive status to family before receiving ART and this proportion increased to $96.7 \%$ at the 24-month mark. Among those who had disclosed their HIV positive status to their family, most of them were satisfied with their decision to disclose; $90.4 \%$ of patients had received family support at baseline, $91.8 \%$ at 6 months, $95.5 \%$ at 12 months, and $94.3 \%$ at 24 months-significantly higher than that at baseline. Most patients (55.2\% and 84.5\%) had received encouragement as well as psychological, financial and physical care support from their families at the baseline and at the 24-month survey.

Participants' perception of family support increased over time. The proportion of patients who did not feel discriminated against by their families was $87.2 \%$ at baseline, $90.4 \%$ at 6 months, $90.0 \%$ at 12 months, and $94.5 \%$ at 24 months. At baseline, $28.1 \%$ of the patients reported not visiting family because they thought they would not be welcomed, and the rate significantly decreased to $13.3 \%$ at the time of the 24 month survey. The rate of patient fear of abandonment by family significantly decreased from $20.7 \%$ at baseline to $8.4 \%$ at 24 months (Table 3 ).

\section{Effect of family support and discrimination on QOL}

GEE analysis was used to study the factors regarding family support and discrimination and their influence on overall quality of life further. Eight factors related to family support and discrimination were significantly associated with the overall quality of life scores: disclosure

Table 1 Recruitment information regarding loss to follow up at assessment times

\begin{tabular}{|c|c|c|c|c|c|c|}
\hline \multirow[t]{2}{*}{ Following up results } & \multicolumn{2}{|c|}{6 month } & \multicolumn{2}{|c|}{12 month } & \multicolumn{2}{|c|}{24 month } \\
\hline & $\bar{N}$ & $\%$ & $N$ & $\%$ & $N$ & $\%$ \\
\hline Completed survey & 267 & 80.42 & 260 & 78.31 & 246 & 74.10 \\
\hline Died & 20 & 6.02 & 22 & 6.63 & 28 & 8.43 \\
\hline Transferred out of facility & 13 & 3.92 & 25 & 7.53 & 27 & 8.13 \\
\hline Lost to follow up & 7 & 2.11 & 20 & 6.02 & 19 & 5.72 \\
\hline Did not complete survey & 25 & 7.53 & 5 & 1.51 & 12 & 3.62 \\
\hline
\end{tabular}


Table 2 Demographic characteristics of people infected with HIV over time

\begin{tabular}{|c|c|c|c|c|c|c|c|c|c|}
\hline \multirow[t]{2}{*}{ Items } & & \multicolumn{2}{|c|}{ Baseline } & \multicolumn{2}{|c|}{ 6-month } & \multicolumn{2}{|c|}{ 12- month } & \multicolumn{2}{|c|}{24 -month } \\
\hline & & $n$ & $\%$ & $n$ & $\%$ & $n$ & $\%$ & $n$ & $\%$ \\
\hline \multirow[t]{3}{*}{ Gender } & Male & 226 & 68.07 & 177 & 53.31 & 179 & 53.92 & 168 & 50.60 \\
\hline & Female & 106 & 31.93 & 90 & 27.11 & 81 & 24.40 & 78 & 23.49 \\
\hline & Missing & 0 & 0.00 & 65 & 19.58 & 72 & 21.69 & 86 & 25.90 \\
\hline \multirow[t]{4}{*}{ Age group } & $20-29$ & 95 & 28.61 & 84 & 25.30 & 78 & 23.49 & 72 & 21.69 \\
\hline & $30-39$ & 105 & 31.63 & 86 & 25.90 & 88 & 26.51 & 79 & 23.80 \\
\hline & $\geq 40$ & 131 & 39.46 & 97 & 29.22 & 94 & 28.31 & 95 & 28.61 \\
\hline & Missing & 1 & 0.30 & 65 & 19.58 & 72 & 21.69 & 86 & 25.90 \\
\hline \multirow[t]{4}{*}{ Level of education } & Primary school or below & 110 & 33.13 & 77 & 23.19 & 76 & 22.89 & 76 & 22.89 \\
\hline & Middle school & 150 & 45.18 & 125 & 37.65 & 123 & 37.05 & 110 & 33.13 \\
\hline & High school or above & 71 & 21.39 & 64 & 19.28 & 61 & 18.37 & 60 & 18.07 \\
\hline & Missing & 1 & 0.30 & 66 & 19.88 & 72 & 21.69 & 86 & 25.90 \\
\hline \multirow[t]{3}{*}{ Marriage status } & Married or cohabitating & 218 & 65.66 & 181 & 54.52 & 174 & 52.41 & 162 & 48.80 \\
\hline & Single/divorced/widowed & 114 & 34.34 & 86 & 25.90 & 86 & 25.90 & 84 & 25.30 \\
\hline & Missing & 0 & 0.00 & 65 & 19.58 & 72 & 21.69 & 86 & 25.90 \\
\hline \multirow[t]{3}{*}{ Occupation } & Farmer/unemployed township citizens & 204 & 61.45 & 158 & 47.59 & 152 & 45.78 & 145 & 43.67 \\
\hline & Employed & 125 & 37.65 & 106 & 31.93 & 105 & 31.63 & 98 & 29.52 \\
\hline & Missing & 3 & 0.90 & 68 & 20.48 & 75 & 22.59 & 89 & 26.81 \\
\hline \multirow[t]{3}{*}{ Live alone } & Yes & 43 & 12.95 & 32 & 9.64 & 31 & 9.34 & 30 & 9.04 \\
\hline & No & 247 & 74.40 & 205 & 61.75 & 200 & 60.24 & 184 & 55.42 \\
\hline & Missing & 42 & 12.65 & 95 & 28.61 & 101 & 30.42 & 118 & 35.54 \\
\hline \multirow[t]{4}{*}{ Monthly household incomes } & $<500 \mathrm{RMB}$ & 95 & 28.61 & 75 & 22.59 & 74 & 22.29 & 71 & 21.39 \\
\hline & $500-\mathrm{RMB}$ & 88 & 26.51 & 69 & 20.78 & 68 & 20.48 & 65 & 19.58 \\
\hline & $1000-\mathrm{RMB}$ & 125 & 37.65 & 101 & 30.42 & 100 & 30.12 & 97 & 29.22 \\
\hline & Missing & 112 & 33.73 & 87 & 26.20 & 90 & 27.11 & 99 & 29.82 \\
\hline
\end{tabular}

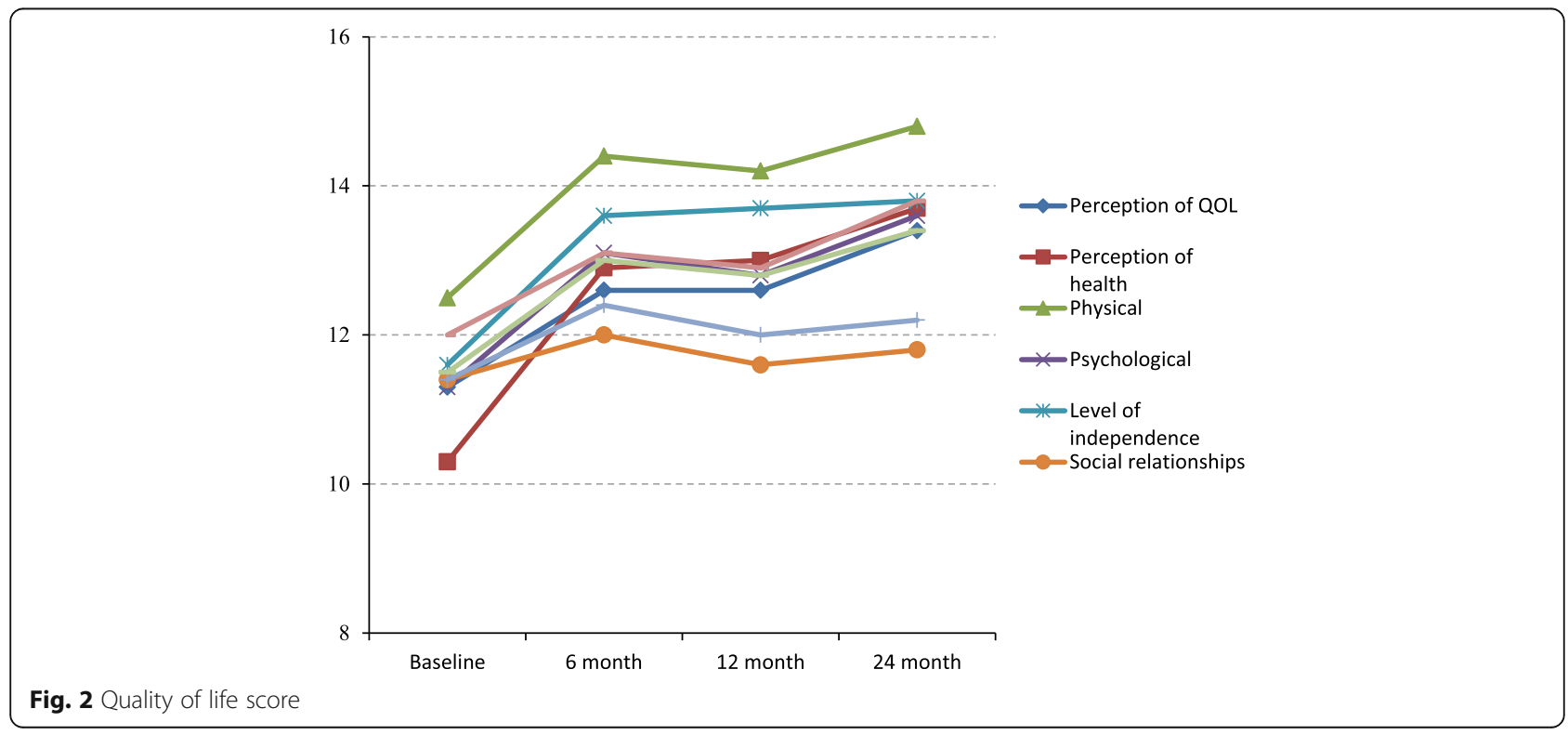


Table 3 Family support and discrimination over time

\begin{tabular}{|c|c|c|c|c|c|c|c|c|c|}
\hline \multirow[t]{2}{*}{ Items } & & \multicolumn{2}{|c|}{ Baseline } & \multicolumn{2}{|c|}{6 month } & \multicolumn{2}{|c|}{12 month } & \multicolumn{2}{|c|}{24 month } \\
\hline & & $n$ & $\%$ & $n$ & $\%$ & $n$ & $\%$ & $n$ & $\%$ \\
\hline \multirow[t]{2}{*}{ Disclosed HIV positive status to family } & Yes & 265 & 81.3 & 232 & 92.8 & 242 & 93.1 & 237 & 96.7 \\
\hline & No or no any family & 61 & 18.7 & 18 & 7.2 & 18 & 6.9 & 8 & 3.3 \\
\hline \multirow[t]{2}{*}{ Family provides supports } & No & 27 & 9.6 & 20 & 8.2 & 10 & 4.5 & 13 & 5.7 \\
\hline & Yes & 254 & 90.4 & 224 & 91.8 & 210 & 95.5 & 217 & 94.3 \\
\hline \multirow[t]{2}{*}{ Family provides psychological support } & Yes & 228 & 80.3 & 193 & 79.1 & 186 & 84.5 & 180 & 78.3 \\
\hline & No & 56 & 19.7 & 51 & 20.9 & 34 & 15.5 & 50 & 21.7 \\
\hline \multirow[t]{2}{*}{ Family provides financial support } & Yes & 207 & 72.9 & 176 & 72.1 & 147 & 66.8 & 127 & 55.2 \\
\hline & no & 77 & 27.1 & 68 & 27.9 & 73 & 33.2 & 103 & 44.8 \\
\hline \multirow[t]{2}{*}{ Family provides physical care support } & yes & 182 & 64.1 & 175 & 71.7 & 164 & 74.5 & 149 & 64.8 \\
\hline & No & 102 & 35.9 & 69 & 28.3 & 56 & 25.5 & 81 & 35.2 \\
\hline \multirow[t]{2}{*}{ Satisfaction with decision to disclose HIV+ status to family } & Satisfied/Nery satisfied & 224 & 84.8 & 186 & 80.5 & 180 & 86.1 & 199 & 90.5 \\
\hline & Somewhat (or not) satisfied & 40 & 15.2 & 45 & 19.5 & 29 & 13.9 & 21 & 9.5 \\
\hline \multirow[t]{2}{*}{ Felt discrimination from family } & Yes & 35 & 12.8 & 22 & 9.6 & 21 & 10.0 & 12 & 5.5 \\
\hline & Never & 239 & 87.2 & 207 & 90.4 & 189 & 90.0 & 207 & 94.5 \\
\hline \multirow{2}{*}{$\begin{array}{l}\text { Patients have found themselves not visiting family because } \\
\text { patients thought they would not be welcomed }\end{array}$} & Yes & 79 & 28.1 & 45 & 18.7 & 39 & 18.1 & 30 & 13.3 \\
\hline & Never & 202 & 71.9 & 196 & 81.3 & 176 & 81.9 & 195 & 86.7 \\
\hline \multirow[t]{2}{*}{ Patient fears abandonment by family } & Yes & 50 & 20.7 & 37 & 16.2 & 24 & 12.0 & 18 & 8.4 \\
\hline & No & 192 & 79.3 & 191 & 83.8 & 176 & 88.0 & 197 & 91.6 \\
\hline
\end{tabular}

of HIV positive status, family support, psychological support from family, physical care support from family, satisfaction with decision to disclose HIV positive status, no experience of discrimination by family, continuation of visits to family, no fear of abandonment by family. These all were significantly associated with higher patient QOL scores (Table 4).

\section{Discussion}

In the study, results showed the percentage of participants who reported that they felt discrimination from family to be smaller than in other countries [32, 33], and it decreased significantly from $12.8 \%$ at baseline to $5.5 \%$ at 24 months. Moreover, the quality of life scores increased alongside increases in family support and decreased in response to discrimination from family during ART treatment. However, the speed and magnitude of improvement were greatest during the first 6 months after ART initiation. They plateaued between 6 and 12 months for most QOL domains. Improved physical symptoms based on CD4 cell counts, hemoglobin, total lymphocyte counts, creatinine (UI/L), amylase, and lipase at the baseline may explain the initial decrease and subsequent increase in domains, such as physical health, psychological health, social relationships, and spirituality. Moreover, results showed that the demographics and experiences of the initial participants who left the study were representative of the entire population studied.
That is, the attrition rate did not affect the results. Many HIV-infected patients (75.7\%) had already developed symptoms when they began ART; Zhang reported that approximately $81 \%$ of HIV-infected patients in China had symptoms when they began ART [30]. Another study indicated that the QOL of patients with symptoms would see more pronounced improvements than those without symptoms after ART [33]. Generally, with the increase of therapy time, the QOL of people infected with HIV showed a rising trend from baseline to 24 months. However, more in-depth research is needed to better understand the underlying causes for the plateau and, in some cases, decrease. In particular, greater attention should be paid to patients after 6 months in order to continuously improve patient quality of life. A positive diagnosis of HIV can also increase the discrimination from the patients themselves, which entails not only physical but also significant psychosocial consequences. In the study, $20.7 \%$ of people infected with HIV feared abandonment by their families, $28.1 \%$ of patients at baseline have found themselves not visiting family because they thought they would not be welcome, and there were significant differences in discrimination from patients themselves and QOL. HIV's involvement in the central nervous system and other parts of the physical body are particularly stressful for patients themselves because the infection is incurable and usually accompanied both by social stigma and symptoms that impair both 
Table 4 Impact of family support, discrimination, clinical indicators, and demographic characteristics on overall quality of life

\begin{tabular}{|c|c|c|c|c|}
\hline Items & & $O R$ & $95 \% \mathrm{Cl}$ & $P$ \\
\hline \multirow[t]{2}{*}{ Disclosed HIV positive status to family } & No & 1.0 & & \\
\hline & Yes & 1.343 & $1.02-1.75$ & $0.045^{*}$ \\
\hline \multirow[t]{2}{*}{ Family provides support } & No & 1.0 & & \\
\hline & Yes & 2.74 & $1.68-4.47$ & $0.040^{*}$ \\
\hline \multirow[t]{2}{*}{ Family provides psychological support } & No & 1.0 & & \\
\hline & Yes & 1.356 & $0.63-1.19$ & $0.040^{*}$ \\
\hline \multirow[t]{2}{*}{ Family provides physical care support } & No & 1.0 & & \\
\hline & Yes & 2.72 & $1.41-5.27$ & $0.029^{*}$ \\
\hline \multirow[t]{2}{*}{ Satisfaction with decision to disclose HIV+ status to family } & Somewhat (or not) satisfied & 1.0 & & \\
\hline & Satisfied/Nery satisfied & 1.61 & $1.18-2.18$ & $0.037^{*}$ \\
\hline \multirow[t]{2}{*}{ Felt discrimination from family } & Yes & 1.0 & & \\
\hline & Never & 1.30 & $1.07-1.59$ & $0.041^{*}$ \\
\hline \multirow{2}{*}{$\begin{array}{l}\text { Patients have found themselves not visiting family because } \\
\text { patient thought they would not be welcomed }\end{array}$} & Yes & 1.0 & & \\
\hline & Never & 1.65 & $0.23-1.74$ & $0.035^{*}$ \\
\hline \multirow[t]{2}{*}{ Patient fears abandonment by family } & Yes & 1.0 & & \\
\hline & Never & 2.05 & $1.49-2.82$ & $0.025^{*}$ \\
\hline \multirow[t]{2}{*}{ Gender } & Female & 1.0 & & \\
\hline & Male & 0.72 & $0.61-0.85$ & 0.056 \\
\hline \multirow[t]{5}{*}{ Education level } & No formal education & 1.0 & & \\
\hline & Primary school & 1.05 & $0.62-1.74$ & 0.932 \\
\hline & Secondary school & 0.95 & $0.57-1.58$ & 0.921 \\
\hline & High school & 0.89 & $0.53-1.50$ & 0.822 \\
\hline & University or above & 0.97 & $.055-1.72$ & 0.963 \\
\hline \multirow[t]{5}{*}{ Marital status } & Married and cohabitating & 1.0 & & \\
\hline & Cohabiting but not married & 0.73 & $0.53-1.00$ & 0.321 \\
\hline & Never married and not cohabitating & 1.60 & $1.18-2.18$ & 0.122 \\
\hline & Divorced/separated \& not cohabitating & 0.81 & $0.62-1.05$ & 0.409 \\
\hline & Widowed and not cohabitating & 1.91 & $1.10-3.31$ & 0.242 \\
\hline Income & - & 1.63 & $1.04-2.57$ & 0.281 \\
\hline Age & - & 1.00 & $0.99-1.01$ & 0.978 \\
\hline CD4 cell count & - & 1.22 & $0.87-1.71$ & 0.559 \\
\hline \multirow[t]{4}{*}{ AIDS staging } & 1 & 1.0 & & \\
\hline & 2 & 0.89 & $0.59-1.36$ & 0.786 \\
\hline & 3 & 0.73 & $1.31-1.56$ & 0.321 \\
\hline & 4 & 0.81 & $0.66-1.14$ & 0.317 \\
\hline
\end{tabular}

${ }^{*}$ means $P<0.05$ and there were statistically significance

cognitive and physical function. These fears may become significant enough to stress social and family relationships, which adversely affects the quality of care, treatment outcomes, and QOL of people infected with HIV.

GEE analysis revealed that nearly all of the family factors were significantly closely associated with overall quality of life scores of the patients. Among these factors, whether the patient has disclosed his or her HIV status to family, whether the family provided supports, and whether the patients were satisfied or very satisfied with their decision to disclose their HIV-positive status to family were associated with higher overall quality of life scores. These results remind us that in order to improve overall patient quality of life, especially in the context of Chinese culture, we must actively provide counselling services to encourage patients to disclose their HIV status to their families earlier. Because families can only provide the support that their HIV-positive 
relatives need if they know that it is needed, disclosure to family members is imperative, and strategies to encourage people infected with HIV to disclose their health conditions to family after diagnosis must be developed. For example, the community, especially clinicians who work with families affected by HIV, need to address the discrimination and stigma issues associated with disclosure in order to increase social support in an attempt to reduce any negative emotional impact that disclosure may have on people infected with HIV. In addition, many studies have suggested that, in general, there is a positive relationship between income and quality of life $[34,35]$. In this study, results showed there is no statistically significant relationship between family income and quality of life $(P>0.05)$ although family income was found to vary slightly across different periods.

In this study, most participants disclosed their HIV status to family members and the rates increased significantly from $81.3 \%$ at baseline to $96.7 \%$ at 24 months. More than $90 \%$ of the participants received support from their families and the proportion remained high at 12-months and 24-months. These results indicated that, as has been found in Chinese culture, family were the people the patients were most likely to trust and to play the most important role in providing support [36]. Therefore, more efforts must be made to reduce the discrimination and stigma associated with HIV-positive status from patients' families. Additionally, patients' own doubts regarding their sense of belonging negatively influenced their overall quality of life. For example, many patients who did not limit family visits because they believed that they would not be welcomed or did not fear abandonment by family enjoyed a greater overall quality of life. This suggests that more psychological support and counselling to reduce patients' self-perceived stigma and discrimination is also important. Moreover, greater effort should be made to provide training and support to the families of PLHIV so that patients receive more effective home-based care and support. These efforts could include mobilizing volunteers to visit families of individuals with AIDS, educating co-workers and family members about basic care issues and putting them in touch with referral networks of health facilities and welfare agencies, assisting with household chores, and providing psychological support.

\section{Limitations}

The present study has some limitations that should be acknowledged. The respondents were recruited solely among individuals actively seeking routine medical care. Those who did not keep regular clinic appointments or peer organization visits could not be included. The results of this study may not be generalizable to all HIV-positive people in China. Moreover, the face-to-face interviews, the assessment of readiness with regard to family and peer support and the administration of the questionnaire by the research team may have led to social desirability biases or affected QOL scores and related results. Nurses, counsellors, and research staff were trained to conduct the interviews in a non-judgmental and objective way and the changes over time were consistent across study sites. Missed observations due to participants dropping out of the study or missed appointments could have caused outcome bias. However, a weighted GEE method was used based on the bias parameters regarding missing data, and the cases of demographics and experiences of the initial participants who left the study were analysed. Overall the results indicated that the participants who left the study could be representative of the entire population studied. In this way, the attrition rate may not have affected the results. Self-reporting data may also have introduced bias. We did not identify any specific association between young men and the fact that about $15 \%$ of all people infected with HIV are young people aged 15 to 24. Further research focusing on family support and young people is urgently needed.

\section{Conclusions}

Family support and either no or very limited discrimination was found to contribute to QOL among people infected with HIV, which tended to improve significantly as ART continued. Strategies to improve and strengthen family support and care for PLWHA and promote HIV screening among high-risk populations should be developed and implemented by both policy makers and researchers. For example, the community, especially clinicians who work with families affected by HIV, must encourage high-risk individuals to undergo HIV testing regularly and to address discrimination and stigma associated with disclosure in order to encourage early initiation of ART and increase the QOL of PLWHA.

\section{Additional file}

Additional file 1: Multilingual abstracts in the five official working languages of the United Nations. (PDF $735 \mathrm{~kb}$ )

\section{Abbreviations}

ART: antiretroviral therapy; GEE: generalized estimating eqs.; HR-QOL: healthrelated quality of life; PLWHA: people living with HIV/AIDS; QOL: quality of life

\section{Acknowledgments}

We would like to thank all study participants for their participation.

\section{Availability of data and materials}

All of the principal data are included in the results. Additional materials with further details may be obtained from the corresponding author.

Authors' contributions

All authors take responsibility for the structure of this paper. JX and ZM conducted the literature review and data analysis. JX drafted the paper. All 
authors contributed to the study's conception and design, interpretation of the data, and critical revisions to the paper. All authors have approved the final version for submission.

\section{Funding}

The study was supported in part by grants from the Program of 15 Years China AIDS Antiretroviral Treatment of Economic Evaluation and Medicare Payment Mode Studies (project no. 20163000254).

\section{Ethics approval and consent to participate}

All participates signed their own names on the informed consent form included in our questionnaires. Individual confidentiality was protected as part of the management of individual information and the processing of personal data. The study protocol and consent procedure were approved by the FHI 360 Protection of Human Subjects Committee, the local Guangxi Institutional Review Board, and the Office of International Ethics.

\section{Consent for publication}

All authors have reviewed the content and have approved the manuscript for submission.

\section{Competing interests}

The authors declare that they have no competing interests.

\section{Author details}

${ }^{1}$ Research Center for Public Health, School of Medicine, Tsinghua University, Beijing, China. ${ }^{2}$ Fukangda Health International Science \& Technology, Beijing, China. ${ }^{3}$ The Paul H. Nitze School of Advanced International Studies, The Johns Hopkins University, Baltimore, USA. ${ }^{4}$ Department of Sociology, Tsinghua University, Beijing, China. ${ }^{5}$ Center for Global Health and Infectious Diseases of Tsinghua University, Beijing, China.

\section{Received: 11 January 2017 Accepted: 3 October 2017}

\section{Published online: 21 November 2017}

\section{References}

1. NCAIDS, NASTD, China CDC. Update on the AIDS/STD epidemic in China and main response in control and prevention in the first quarter of 2016. Journal for China AIDS/STD 2016;22:311. (in Chinese).

2. Hao $Y$, Cui $Y$, Sun $X H$, Guo W, Xia G, Ding ZW, et al. A retrospective study of HIV/AIDS situation: a ten-year implementation of "four frees and one care" policy in China. Chin J Dis Contl Prev2014;18:369-374. (in Chinese).

3. Li X, He G, Wang H, Williams A. Consequences of drug abuse and HIV/AIDS in China: recommendations for integrated care of HIV-infected drug users. AIDS Patient Care STDs. 2009;23:877-84.

4. Ethics Committee of American Society for Reproductive Medicine. Human immunodeficiency virus (HIV) and infertility treatment: a committee opinion. Fertil Steril. 2015:104:e1-8.

5. Au A, Chan I, Li P, Chuang R, Po LM, Yu P. Stress and health-related quality of life among HIV-infected persons in Hong Kong. AIDS Behav. 2004;8:119-29.

6. Mayor AM, Gomez MA, Rios-Oliveras E, Huntermellado RF. Mortality trends of HIV-infected patients after the introduction of highly active antiretrovira therapy: analysis of a cohort of 3,322 HIV-infected persons. Ethn Dis. 2005;15:57-62.

7. Willard S. Relationship of emotional intelligence and adherence to combination antiretroviral medications by individuals living with HIV disease. J Assoc Nurses AIDS Care. 2006;17:16-26.

8. Albert WW, Gifford A, Asch S, Cohn S. Quality-of-care indicators for HIV/AIDS. Dis Manag Health Out. 2000;7:315-30.

9. Malee K, Williams PL, Montepiedra G, Nichols S, Sirois PA, Storm D, et al. The role of cognitive functioning in medication adherence of children and adolescents with HIV infection. J Pediatr Psychol. 2009;34:164-75.

10. Li L, Wu Z, Wu S, Jia M, Lieber E, Impacts LY. Of HIV/AIDS stigma on family identity and interactions in China. Fam Syst Health. 2008;26:431-42.

11. Dos Santos MM, Kruger P, Mellors SE, Wolvaadrt G, Ryst EVD. An exploratory survey measuring stigma and discrimination experienced by people living with HIV/AIDS in South Africa: the people living with HIV stigma index. BMC Public Health. 2014;14:80

12. Sinyangwe $G$. Descriptive study of HIV/AIDS-related stigma experienced by people living with HIV/AIDS (PLWHA) in healthcare settings offering family planning and/or HIV services in Kapiri-Mposhi, Zambia. Acta Neurol. 2012;2:382-9.
13. Joseph EB, Bhatti RS. Psychosocial problems and coping patterns of HIV seropositive wives of men with HIV/AIDS. Soc Work Health Care. 2004;39:29-47.

14. Jones DJ, Beach SR, Forehand R, Foster S. Self-reported health in HIVpositive African American women: the role of family stress and depressive symptoms. J Behav Med. 2003;26:577-99.

15. Kebede MA, Haidar J. Factors influencing adherence to the food by prescription program among adult HIV positive patients in Addis Ababa, Ethiopia: a facility-based, cross-sectional study. Infect Dis Poverty. 2014;3:1-10.

16. Gore-Felton C, Rotheram-Borus MJ, Weinhardt LS, Kelly JA, Lightfoot M, Kirshenbaum SB, et al. The healthy living project: an individually tailored, multidimensional intervention for HIV-infected persons. AIDS Educ Prev. 2005; 17:21-39.

17. Ji G, Li L, Lin C, Sun S. The impact of HIV/AIDS on families and children -a study in China. AIDS. 2007;21:S157-61.

18. Mathivha TM. The role of family support and HIV/AIDS stigma on adherence and non-adherence to antiretrovirals at Nzhelele in Limpopo Province, South Africa. 2012. http://ulspace.ul.ac.za/handle/10386/767. Accessed on 1 Sept 2017.

19. Murphy DA, Moscicki B, Vermund SH, Muenz LR. Psychological distress among HIV+ adolescents in the REACH study: effects of life stress social support and coping. J Adolescent Health. 2000;27:391-8.

20. Prado G, Feaster DJ, Schwartz SJ, Pratt IA, Smith L, Szapocznik J. Religious involvement, coping, social support, and psychological distress in HIVseropositive African American mothers. AIDS Behav. 2004;8:221-35.

21. Przybyla SM, Golin CE, Widman L, Grodensky CA, Earp JA, Suchindran C. Serostatus disclosure to sexual partners among people living with HIV: examining the roles of partner characteristics and stigma. AIDS Care. 2013;25:566-72

22. Bhagwanjee A, Petersen I, Akintola O, George G. Bridging the gap between VCT and HIV/AIDS treatment uptake: perspectives from a mining-sector workplace in South Africa. Afr J AIDS Res. 2008:7:271-9.

23. Kroeger K, Taylor AW, Marlow HM, Fleming DT, Beyleveld V, Alwano MG, et al. Perceptions of door-to-door HIV counselling and testing in Botswana. Sahara J. 2011:8:171-8

24. Chow EP, Gao L, Chen L, Jing J, Zhang L. Shifting patterns of the HIV epidemic in Southwest China: a case study based on sentinel surveillance, 1995-2012. AIDS Patient Care STDs. 2015:29:314-20.

25. Ferguson L, Grant AD, Lewis J, Kielmann K, Watson-Jones D, Vusha S, et al. Linking women who test HIV-positive in pregnancy-related services to HIV care and treatment Services in Kenya: a mixed methods prospective cohort study. PLoS One. 2014:9:e89764.

26. Bor R, Plessis PD, Russell M. The impact of disclosure of HIV on the index patient's self-defined family. J Fam Ther. 2004;26:167-92.

27. D'Cruz P. Engulfing darkness: the impact of HIV/AIDS on the family. Fam Soc. 2002;83:416-30.

28. Davidson JE. Family-centered care: meeting the needs of patients' families and helping families adapt to critical illness. Crit Care Nurse. 2009;29:28-34.

29. Bazant E, Sarkar S, Banda J, Kanjipite W, Reinhardt S, Shasulwe H, et al. Effects of a performance and quality improvement intervention on the work environment in hiv-related care: a quasi-experimental evaluation in zambia. Hum Resour Health. 2014;12:73.

30. Zhang F, Dou Z, Ma Y, Zhao Y, Liu ZF, Bulterys M, et al. Five-year outcomes of the China National Free Antiretroviral Treatment Program. Ann Intern Med. 2009:151:241.

31. Pereira M, Martins A, Alves S, Canavarro MC. Assessing quality of life in middle-aged and older adults with HIV: psychometric testing of the WHOQOL-HIV-Bref. Qual Life Res. 2014;23:2473-9.

32. Busza JR. Promoting the positive: responses to stigma and discrimination in Southeast Asia. AIDS Care. 2001:13:441-56.

33. Paxton S, Gonzales G, Uppakaew K, Abraham K. AIDS-related discrimination in Asia. AIDS Care. 2005:17:413-24.

34. Zhou WY, Ji K. The health status and quality of life of rural residents under different income in China. Chinese J Health Pol. 2011:04:54-9. (in Chinese)

35. Yang Y, Zhang KL, Wang KR, Li ZR, Yan HW, Zhao YT, et al. Study on quality of life and related factors among people living with hiv/aids. Journal for China Aids/std 2005:11:244-246. (in Chinese).

36. The UN. Theme Group on HIV/AIDS in China. HIV/AIDS: China's titanic peril. 2001 Report of the AIDS situation and need assessment report. http://www. wisdomofwhores.com/wp-content/uploads/2010/11/ChinaAIDSTitanicChallenge. pdf. Accessed on 1 Sept 2017. 